\title{
Waldorf Teacher Training in China from the Perspective of Anthroposophy
}

\author{
Liang Zhanhua ${ }^{a, *}$, Gu Qin ${ }^{\mathrm{b}}$ and Zheng Qiyun ${ }^{\mathrm{c}}$ \\ School of Education, Ningxia University, Ningxia 750021, China

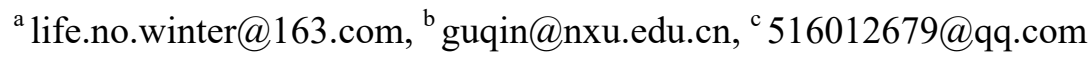 \\ *corresponding author
}

Keywords: Anthroposophy, Waldorf education, holistic education, artistic teaching, teacher training

\begin{abstract}
Waldorf Education appeared in China in 2004, and then spread everywhere in China. The rapid development of it requires more and more high-quality teachers, thus setting off a wave of teacher training. The author has analyzed the development of it in china especially from the training aspects, such as: the needs of the Waldorf teacher training from the society, the organization and management, the training ways, the trainers and trainees, the training content, the feedback and evaluation, and so on. The author hopes to bring a different perspective and reference for all the trainers in traditional education. Also hope to help more people understand the the development of Waldorf teacher training in China.
\end{abstract}

\section{Introduction}

March 7th, 2017, Freunde der Erziehungskunst Rudolf in Germany Steiners (address) officially released the first "Global Waldorf List this year" (two versions per year). There was a total of 1092 independent Waldorf schools, 1857 Waldorf kindergartens and 646 special education centers were established in 64 countries. In this version of the list, China, a total of 7 schools, namely: Beijing Lezhi, Beijing Nanshan, Cheng Douhua Telford school, Guangzhou school, Guangzhou School of landscape in Taoyuan, Shaanxi to Hancheng river river, Zhuhai ChunTong and 38 kindergartens. Addition to all these, there are more than 50 Waldorf schools and 600 kindergartens was established all over the country, since China's first Waldorf school was established in September 2004 in Chengdu. At the same time, the Waldorf Education is developing vigorously in public schools and charter schools and the home education.

As a college teacher who has 13 years' experience in the pre-service teacher training. The author became more aware of the superficial and the formality of traditional teacher training. As a movement comes from the folk, Waldorf Education has spread all over the world. Especially in china, it is always keep an amazing speed. It is so worthy of attention and thinking.

\section{Waldorf Education: From the Anthroposophy Perspective}

\subsection{About the Anthroposophy}

Anthroposophy is a spiritual science founded by Dr. Rudolf Steiner, a philosopher, scientist, educator in the early part of last century in Austria. It seeks to explore the nature of mankind, life, and the whole world especially the nature of spiritual activity in a scientific way. It also seeks to explore the relationship between mankind, wisdom, and all things in the universe. It believes that mankind and the universe are one whole. They have a deep emotional attribution and share the same fate of breathing. The emergence and development of every person are in some way strikingly consistent with the evolution of the whole earth and the history of human civilization.

Dr Steiner used the natural science to make human spiritual experiences, including super sensory spiritual experiences can be understood and communicated. He believed that each person can 
develop their ability to acquire a direct spiritual experience in a certain way. Knowing the world / themselves and changing the world / themselves are at the same time. We everybody needs to grow up in spiritual world, and needs to do everything corresponding to what we have known, so that the pure thinking can be taken into an advanced spiritual existence and can connect to the universe. So each higher-self and advanced spiritual existence can become the creator of the world together. According to Steiner, modern people should be aware of the spiritual reality, whether as individuals or. And that personal life and social life all should be built on it.

\subsection{About the Waldorf education}

Based on the deep thinking of the serious social problem after World War I. Dr. Steiner set up the first Waldorf School at the invitation of a cigarette factory's boss in German for the children of employees of the factory. Because this factory's name was Waldorf, so named the school Waldorf School. The school's teaching methods and content are in full accordance with Dr. Steiner's own understanding of people and their development. Since then, Waldorf Education became a model of future education and has expanded to different countries with different cultural backgrounds and social values. Waldorf Education is in the ascendant in china because of the harmony with our traditional Chinese culture.

Waldorf Education is so different from all those traditional education because of the profound philosophical background, the unique outlook on children and the systematic teaching methods. Based on Steiner's theory of Anthroposophy, the most important point of Waldorf education is that mankind does not only exist as a physical body, but even more importantly as a spiritual existence. Therefore, it advocates the education of the mind. In other words, it is the the natural education towards health which will dedicate to the harmonious development of body, mind and spirit. Therefore, Waldorf Education pursues artistic educational methods to a great extent.

From Waldorf Education, prospective: people totally has 4 basic dimensions. In addition to the physical body (such as the mineral kingdom), people also has the etheric body (such as plants kingdom), astral body (the emotional body, such as the animal kingdom) and I (only humans have). The purpose of education is to bring up healthy and balanced children, based on full respect for the 4 basic dimensions development order. Children develop different abilities gradually in different stages of life to understand the world and themselves. Each life takes 7 years as a cycle to grow up gradually and it always shows a certain growth law. Education should conform to the law. If it is violated or destroyed, children will lose the balance and health. So do affect the society in every aspect. Children's development stage can be broadly divided into the following three stages in Waldorf Education:

(1)From birth to Changing teeth, about 0-7 years old.

In this period, children mainly develop their willing. They could not distinguish the world and the self. They are integral to the whole world and share an etheric body with their mother. They learn everything from their surroundings and develop through imitation. This period should make children to experience "goodness" from all levels instead of intellectual influence.

(2) From Changing teeth to puberty, about 7-14 years old.

In this period, children mainly develop their feeling primarily through the mind experience. The protection of astral body has not been completely opened yet in this period. It is still not suitable to use too abstract concept to teach. We should adopt the way of using pictures, images and examples to promote study and guide their imagination. In this period Education should allow children to experience "beauty" at all levels.

(3) From puberty to adolescence, about 14-21 years old.

In this period, children mainly develop their thinking. Astral body protects are unlocked. The mind obtains complete freedom, so it can be subjected to exterior influence. Based on the development of willing and feeling, intellectual and abstract understanding will lead to even more independent judgment and challenge the authority. Education in this period should allow children to experience "truth" at all levels. 
Just for all these, Waldorf Education does not pay more attention to the "children-centered", but to " understanding of the children's development." Therefore, the teacher's main task is to make children's body, mind and spirit get harmonious through the artistic way which is closing to the nature of the world. Thus, who is as a Waldorf Teacher must have higher self-awareness, strong sense of mission and rich artistic talent, strong imagination, reverence, gratitude, love and sacrifice.

\section{An Overview of Waldorf Teacher Training}

\subsection{The Healthy Holistic Education has become a prominent social demand}

Education is a product of the human society development. Its missions are different in different historical stages. More and more social problems arising in today's globalization background with great wealth of material. Our human beings have to rethink the nature of the relationship between material and spirit, man and nature, education and human development.

More and more parents began to pursue a healthy education which can balance the material and spiritual. They even began to shoulder the important task of educating their children by themselves. More and more private schools and home schools quietly rising. More and more people with breadth of vision are exploring new education which conforms to the nature and respect for humanity. More and more people are willing to follow kids' natural development and accompany to achieve self-growth. As a kind of education helping children recognize themselves and become healthy and harmonious themselves, Waldorf Education just cater to the great internal demands of these people.

\subsection{The Development of Waldorf Teacher Training in China}

In 2004, Chengdu launched the first Chinese Waldorf school, only a few teachers had studied Waldorf Education abroad, the others had went to Thailand, Australia and the United States to participate in short-term training. Sending new teachers to foreign countries for training is a tough move without the generous support from teacher's family, the parents of the school. In 2007, 3 years after Chengdu Waldorf School was founded. The first 3 years part-time training for primary school was started under the well arrangement planed by Chengdu Waldorf School and well curriculum designed by Grandpa Ben. There were all over the country's more than 120 people crowded in less than 70 square learning classrooms. A lot of them founded their Waldorf Schools in other areas. They played a key role in the development of Waldorf Education in china. Chengdu Waldorf Training Center, so is called Waldorf "Huangpu Military Academy".

Since then, different local training programs were established all over the country. All these programs mainly can be divided into 3 categories and different professional division projects:

Kindergarten teacher training programs: Beijing Spring Valley, Beijing Tianxiaxi, Xi'an, Chengdu, Guangzhou, Fuzhou, etc.

Primary school teacher training programs: Beijing Spring Valley, Xi'an, Chengdu, Guangzhou etc.

High school teacher training programs: Chengdu, Beijing Spring Valley, Xin zhuang Normal and Beijing Lezhi run jointly.

All above the training programs almost started based on the first training project in Chengdu, in 2004. They all are designed and implemented by the international scholars, artists, and senior Waldorf teachers from all over the world. They all are usually a 3-years cycle. Totally 6-8 phases and 3 weeks per phase. In addition to the above 3 types of training programs, there are more other professional programs, such as: school and community management, art, drama, medicine, architecture, space biological farming, maths, English, sports etc. There are also many other various professional training programs distributed in China.

In addition to all these above programs, many Waldorf schools also carried out training programs only for their own teachers. In particular, the spring valley college, founded in 2010, has started a full-time staff training since 2012. In 2014, Beijing Xinzhuang normal university also began 1 year full-time training. In the autumn of 2016, Chengdu Waldorf school started a training program 
especially for those pre-service primary teachers in Sichuan Normal University. In the same year, Chengdu Waldorf School first started the school-based curriculum for adults.

All these different kinds of Waldorf training have been coming up continually in china in the past 10 years. It has expanded our learning resources and space, has brought fresh air and nutrients for us every trainer.

\section{The Characteristics of Waldorf Teacher Training in China}

\subsection{Spiritual and practical training goals}

Although all those training programs have different objectives, they all have the same goal, because they all are rooted in the Anthroposophy theory and spiritual strength are especially valued and developed in all programs. They all aim at making teachers have full curiosity, enthusiasm and awe for the world, clear their inner world, find their own mission through developing deep and alive thinking, and to practice firmly.

In order to better support trainees successfully reach the spiritual goal and practice effectively during the training process, these training programs are locked with distinctive practice goal: (1) Understand the development of life from the overall context of the development of human civilization through continuously exploration of the autobiography research, cosmic evolution, human culture era evolution and the relationship between the individual development and the evolution of human civilization. (2) Have a more profound understanding of 3 basic dimensions, 4 basic dimensions and 9 basic dimensions of people. (3)Form awareness of oneself, others, and the world. (4) Complete the internal transformation of self, strengthen willpower and creativity. Reconcile scientific methods with humanistic spirit, natural science and meditation, as well as different ways of thinking between the East and the west, and learn to think in the communion of science, art and spirit. (6) Carry out research work independently.

This does not aim at the specific knowledge and skills as the goal, but a highly spiritual significance and practical orientation. This prompt all teachers to pursue their own life values, and make them more effectively to meet those children live in today's continuous culture development and evolution era.

\subsection{Broad and Profound Training Content and Curriculum System}

In order to achieve the above series training objectives, those different training programs are so colorful in curriculum system, content arrangement and design. But they are all linked closely to the theoretical core of Anthroposophy. All these training programs generally involve the following three aspects of the training content:

(1) Theoretical foundations of Anthroposophy. This part is mainly carried out through systematic study of the basic works of Anthroposophy. It aims at cultivating trainees to: think in the communication of science, art and religion, gain internal development and transformation, aware their own, others and the world, strengthen their willpower and creativity, gain the independent research ability and lifelong learning ability, improve the independent personality and find the mission in self-development. In my opinion, this part is the true spirit and value of Waldorf Training. It helps teachers to find their own mission and value of life as a truly independent individual. The confirmation of the mission and the value guide them to keep keen awareness of themselves and the world in daily life and continuous development and improvement, so that they can achieve a meaningful life.

(2) The majors and specialties of Waldorf Training. This part aims at: awareness and insight on children's behavior and development, understanding of the syllabus and teaching methods, organic and artistic perspective, the transformation of teachers role in different stages, good mastery of teaching methods and organizing suitable content for different types of children's needs, improvement of teachers' self-management, class management and parents management, the ability to use a variety assessment methods, persistent learning and persistent practice of internal development, etc. 
Most participants devote to Waldorf Education just because deep thinking about their children's education. So in addition to their educational ideals and enthusiasm, their basic skills of Waldorf Education almost are none. So the practical content is a very important part. Those rich and diverse content including: arts and crafts, music and rhythm, recorder and flute and other instruments playing, speech, drama, eurythmy, gymnastics, sports education, clay, plastic, woven, beeswax game and sewing, form drawing, wet water color painting, powder painting, sculpture and blackboard visual art etc..

(3) Practice and work ability. Practice and probation, listen to lectures, teaching discussion, preparation meeting for every grade, etc. Understand Waldorf school organization, operation and management model based on the 3 basic dimensions community concept, understand the construction of teachers' team and ther cooperation with each other, understand the construction of the relationship between family and school, and know how to promote the work of parents and community activities.

It is particularly worth mentioning is that in addition to the formal curriculum content, daily life of living, the relationship between ourselves and others and the environment together all become the fresh informal curriculum contents. It can be said that everywhere is training and from time to time in Waldorf Training. It combines training with life very well indeed.

Even more gratifying is that, more and more schools begin to think more about the Chinese localization of Waldorf Education after many years practice. More and more experience of teaching practice are increased during the training.

\subsection{Rhythmic and colourful training methods}

Forming good rhythm is the most effective way to establish order, security and health. In Waldorf Education, all activities will take care of the natural rhythm and the rhythm of life, breathing and dynamic balance. All those training programs are very good at this, so they all apply the same process: morning circle, verse reciting, keynote speeches, modular teaching, special group discussion, daily review, end circle etc.. The trainer will arrange relatively flexible activities to help all trainees always be in a relatively balanced state between absorption and relaxation. The inherent training model, as well as the teaching methods of the combination of movement and breathing are also the daily basic rhythm of children's learning at Waldorf school.

In addition to this rhythmic process, many other forms of activities are used also, such as evening forums, writing assignments, readings, specified classroom observation, listen to each other's class, dialogue between teachers and students, inquiry way of communication and interaction. The organic and interactive are integrated to the greatest extent.

It is worth mentioning that there are all will be a cultural night in all the Waldorf training programs which is loved by all trainers and trainees. Trainers and trainees will perform those moved them in an artistic way. It is the most beautiful and authentic feedback of every training.

\subsection{High standard teaching team from all over the world}

Since the teacher training at the Waldorf School in Chengdu, in 2007, the teaching team has always been senior intellectuals, artists and teachers of Waldorf school all over the world. Most of them have advanced in age, many retired or near retirement, completed the main lesson teaching 23 round of 1-8 grade work in their own countries. All of them have a wealth of teaching experience. Some trainers also serve as the instructor of the international Waldorf teacher training program. They are responsible for the guidance and supervision of the development of Waldorf Education in different countries and regions. All those trainers of each training team are from all over the world, they closely cooperate with each other to create good learning environment for the trainees, to

ensure the characteristics of the local curriculum based on the essence of Waldorf education .Although different projects, different teachers, different styles, they all are surprisingly consistent in: reverence for life, love for education, rich teaching experience and these years, they are bringing more and more fresh local cases of their practice for the training. 


\subsection{Diversified trainees full of Education ideal}

The training programs are mainly for teachers and parents of Waldorf school. They also attract attention from all levels of society who are practicing or focusing on the holistic education. At present, those trainees are mainly composed of the following personnel: in-service teachers and preservice teachers from Waldorf schools; Waldorf school parents; practitioners of natural education and home education. Fortunately, under the leadership of Mu Peihua who is the former director of the Zhengzhou Bureau of Education, the majority educators of Zhengzhou traditional schools have also joined the Waldorf teacher training. At the same time, more and more teachers from the traditional schools began to join all these training programs in other places. Although they are from different fields, but they all have a common characteristic is that they also have a better education ideal, and are willing to realize it through their own efforts.

resources, whole-hearted spirit glory. These are always affected the trainees. As Steiner said: "the children are not through what you say or do, but by who you are to learn", what those trainers do is the best interpretation of this saying.

It is worth mentioning that, some local trainers have grown up after continuously practice for

\subsection{Humanized training organization and management}

All these training programs are basically initiated by the organizer, designed and developed by those experienced teachers who are invited from different countries. There are many people support the organization and management of every training program. In order to ensure the flexibility and efficiency of the training, all trainers and supporters will review and reflect all the activities at the end of everyday work to make a timely adjustment. Before the formal training, the related information and requirements will be released through WeChat Group. All trainees can prepare for the coming training in advance with clear goals and needs. During the training, trainers and trainees will be able to communicate with each other through one-to-one interviews and other channels. At the same time, the training programs are usually supported by the teachers and volunteers of the respective training institutions. All trainees will also actively everyday's environment cleaning and maintenance, materials preparation and other related works. From all these work and other informal. all trainees also can experience the principles and spirit of Waldorf Education which enlarged the traditional regular training concept and method that trainers teach and trainees accept.

At the same time, in order to better coordinate all power from every aspect, and better ensure the training quality, CWF (Chinese Waldorf Forum) was established. It's a monument for the development of Chinese Waldorf Education. It plays an important role to ensure the formality of all the training programs.

\subsection{Good transferability}

These well structure of the training programs, especially the course of self-growth, not only can help the trainees to establish a better knowing of the spiritual world and the actual life. It can help them establish a scientific world-view and value-view that will lead them to find their own self and meaning. All these programs are not only limited to the knowledge and skills. So no matter teachers or parents, in-service or pre-service teachers, even the others, they all can get fresh nutrition from the training programs, and transfer them into their daily work and life. Many trainees have chosen to built their own Waldorf School or be a Waldorf teacher in their local areas inspired by these powerful training. They all are exploring towards the health education.

They usually form a strong community of Waldorf education resources after each training programs. They are continuing support each other and sharing the richest resources. It has become a spontaneous but extremely warm folk strength. This strength is becoming more and more stronger and is warming more and more practitioners. 


\section{Summary}

Information technology revolution is so rapidly that it is making people look on intellectual development even more seriously. The materialistic social environment, heavy pressure and the extremely restless life rhythm are constantly spawned a variety of educational problems and social problems. In this case, correct recognition and pursuit of the value and meaning of life is so particularly important. It is inevitably important for us to reconsider the function and value of education, the starting point and standpoint of education, the content of education and the methods and forms of education. The great ancient Greek thinker Socrates once said: education is not indoctrination, but to light the flames. This sentence have just described what the Waldorf Education is doing perfectly. There are so many worthies us to reflect again and again.

The training work of teachers should pay more attention to the following problems: the cognition and awe of life should be given sufficient attention, the education should be thought about in the history line and under the present world background, spirit strength should be pay more attention, the content of education should be consistent with the law of life growth and development and connected with life and the our real world more effectively, imitation of the nature to adjust the education methods consistent with the natural rhythm, teaching scientifically and artistically so that real nurturing can happen effectively, combining the formal curriculum with the informal curriculum, keeping the system as a whole and make sure it as flexible as possible. These are not only applicable to teacher trainers, but also to every teacher's peer.

\section{References}

[1]. The Global Waldorf School list was released in 2017 for the first time, https://hiwaldorf.com/p ost9341

[2]. What are the Waldorf teacher training programs in mainland China, http://hiwaldorf.com/faqs/? How about the charges?

[3]. Michaela Glockler, Stephen Lanhamer, (Ben), Christoph Vichet, Towards Health Education. Michaela Glockler, Stephen Lanhamer, (Ben), et al. Tianjin Education Press, 2013.08

[4]. Rudolf Steiner, Wen Peng, translation, Steiner's Practical Suggestions for Teachers, (Germany), tower school, Guizhou publishing group, Guizhou Education Press, 2013.10

[5]. Rudolf Steiner, The Kingdom of Childhood. Shenzhen press group press, 2014.05 